\title{
Perigraft seroma following Right Modified Blalock Taussig shunt in a child with complex cyanotic heart disease
}

\author{
De Silva DCL ${ }^{1}$, Perera SN ${ }^{1}$, Wijemanne I ${ }^{2}$, Perera LAP ${ }^{3}$, Mahalekamge ${ }^{3}$, Fernando ${ }^{4}$ \\ ${ }^{I}$ Department of Paediatric Cardiology, ${ }^{2}$ Department of Paediatric Cardiothoracic Surgery, \\ ${ }^{3}$ Department of Paediatric Cardiothoracic Intensive Care, ${ }^{4}$ Department of Radiology, \\ Lady Ridgeway Hospital for Children, Colombo, Sri Lanka
}

Correspondence: Dr. D.C.L. De Silva;

Mobile:+94 772988311; e-mail: charithdcl@yahoo.com

\section{Case report}

A three and half year old boy with Tetralogy of Fallot and pulmonary atresia was admitted for cardiac catheterisation to assess suitability for the Rastelli procedure (Total correction of Tetralogy of Fallot with right ventricle to pulmonary artery conduit).

Palliative modified Blalock Taussig (BT shunt) was done in June 2011 as his pulmonary arteries were hypoplastic. A 5mm polytetrafluoroethylene (PTFE) expanded Gore-Tex graft was interposed between the right subclavian and right pulmonary artery through a right posterolateral thoracotomy. Heparin was given for $48 \mathrm{hrs}$ followed by aspirin (3-5 mg/kg per day). Saturation was maintained at a satisfactory level. He did not have postoperative complications. The patient was discharged on the $10^{\text {th }}$ day after the procedure and followed up regularly to assess the growth of branch pulmonary arteries and the shunt function.

Two years after the modified BT shunt, a chest radiograph was taken and it showed a large well demarcated right superior mediastinal mass with no marked tracheal displacement. The radiograph and ultrasonography were suggestive of a seroma around the right modified BT shunt (Figure 1). Cardiac catheterisation revealed a large seroma compressing the right lung with reduced lung arborization of the right upper zone. His right pulmonary artery was not adequately grown when compared to left pulmonary artery. There was no graft compression by the seroma (Figure 2).

The seroma was aspirated, completely, under ultrasound guidance using an $18 \mathrm{G}$ spinal needle (Figure 3A). Aspirate yielded $90 \mathrm{ml}$ of amber coloured fluid (Figure 3B). Post aspiration chest radiograph revealed expanded right lung (Figure 4).

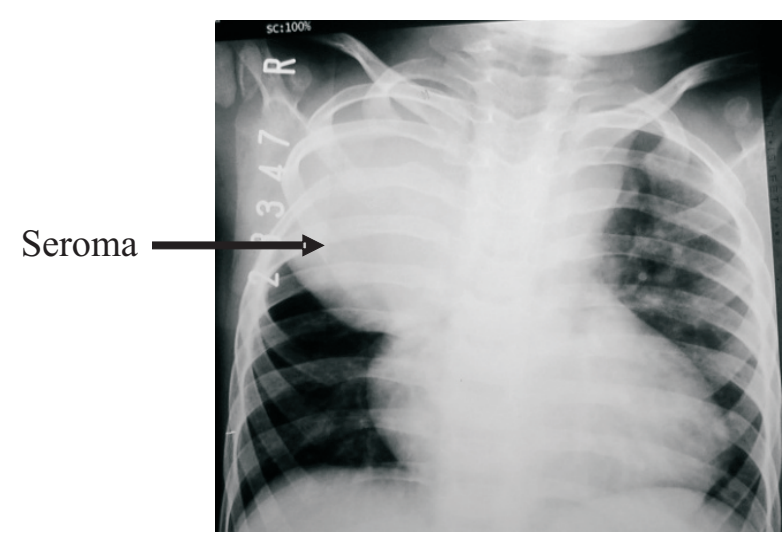

Figure 1: Chest X-ray two years after BT shunt

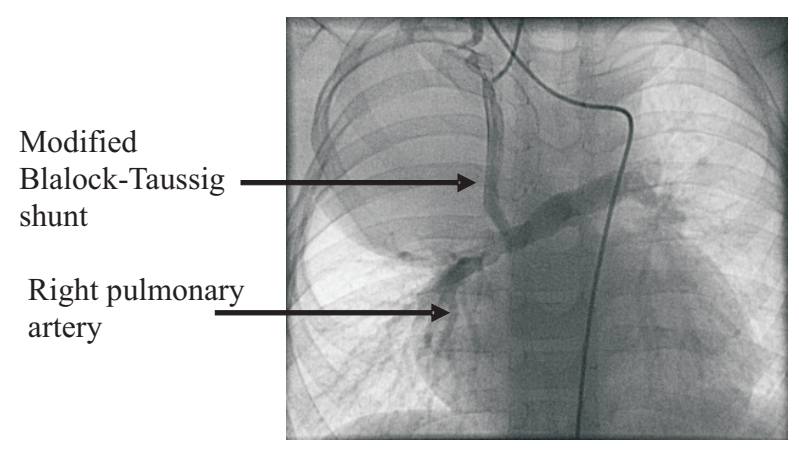

Figure 2: Seroma compressing the right lung with reduced lung arborization of the right upper zone

\section{Discussion}

The original procedure of BT shunt was an end-toside anastomosis in which the subclavian artery was sacrificed $(1,2)$. With the advent of artificial vessels made of materials such as Gore-Tex, a change in the procedure was introduced. In 1976, Gazzaniga et al, (3) were the first team to perform a modified Blalock-Taussig shunt, using a polytetra-fluoroethylene graft (Gore-Tex; W.L. Gore) as an interposition between the subclavian and pulmonary arteries (Figure 5). 
Several well-known complications of the modified BT shunt, such as shunt thrombosis, infection, haematoma, aneurysmal dilatation, mycotic pseudoaneurysm and perigraft seroma have been described. A perigraft seroma is defined as a sterile collection of fluid in a non-secretory wall surrounding the shunt. The cause of the formation of a perigraft seroma is still a matter of debate. One of the most widely accepted theories is that handling of the polytetrafluoroethylene graft causes leakage because of a change from a hydrophobic state into a hydrophilic one. The fluid collection thus contains graft ultrafiltration (transudate) (4).

Perigraft seroma development around a modified Blalock-Taussig shunt is a relatively rare but, nonetheless, well-known complication. In recent literature, the prevalence of this complication has been reported as ranging from $2.5 \%$ to $9.5 \%$. Seroma formation normally takes place within first 2 months following surgery but our patient developed this complication after two years. This indicates the need of maintaining the vigilance and performing routine chest radiographs at regular intervals to detect this complication at pre-symptomatic stage. Cases presenting after 8 years also have been reported (5).
Patients with seroma may present with symptoms such as intermittent stridor, respiratory distress and or episodic desaturation within weeks of surgery. Most seromas reported to have encompassing the graft.

For the diagnosis, chest radiography shows the first sign of the seroma after modified BT shunt. Thoracic sonography also can demonstrate the perigraft seroma and the function of modified BT shunt. Thoracic computed tomography (CT) or magnetic resonance imaging (MRI) may be performed to study perigraft seromas in detail. When seroma is found in a critically ill patient, ultrasonography has an advantage over CT and MRI because of its portability and capability for bedside use.

Treatment modalities includes aspiration using sterile technique with a large bore needle (14 - 18 Guage) or angiocatheter followed by application of pressure dressing that promotes the obliteration of seroma and eventual healing. Chronic seromas as in our case is difficult to obliterate with needle aspiration. It may need closed suction drains to prevent recurrences. In cases with blocked BT shunts, it may need balloon angioplasty or surgical refashioning of the shunt.

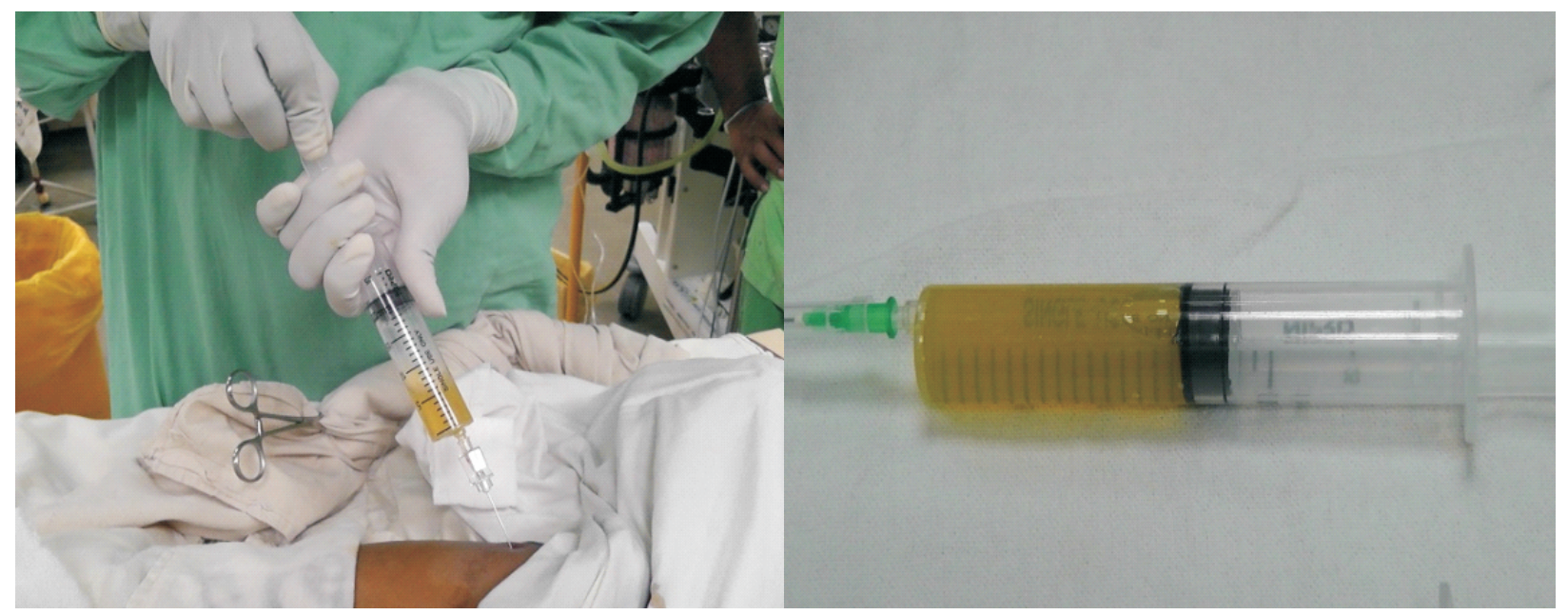

Figure 3: Aspiration of seroma under ultra sound guidance 


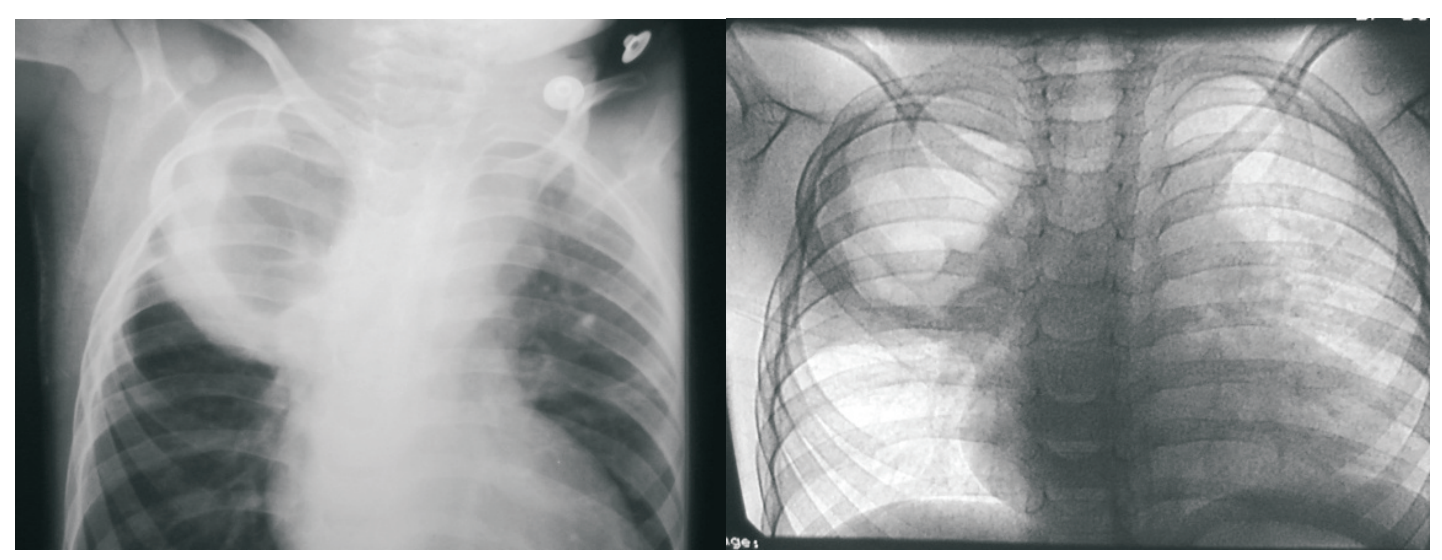

Figure 4: Post aspiration chest X-ray

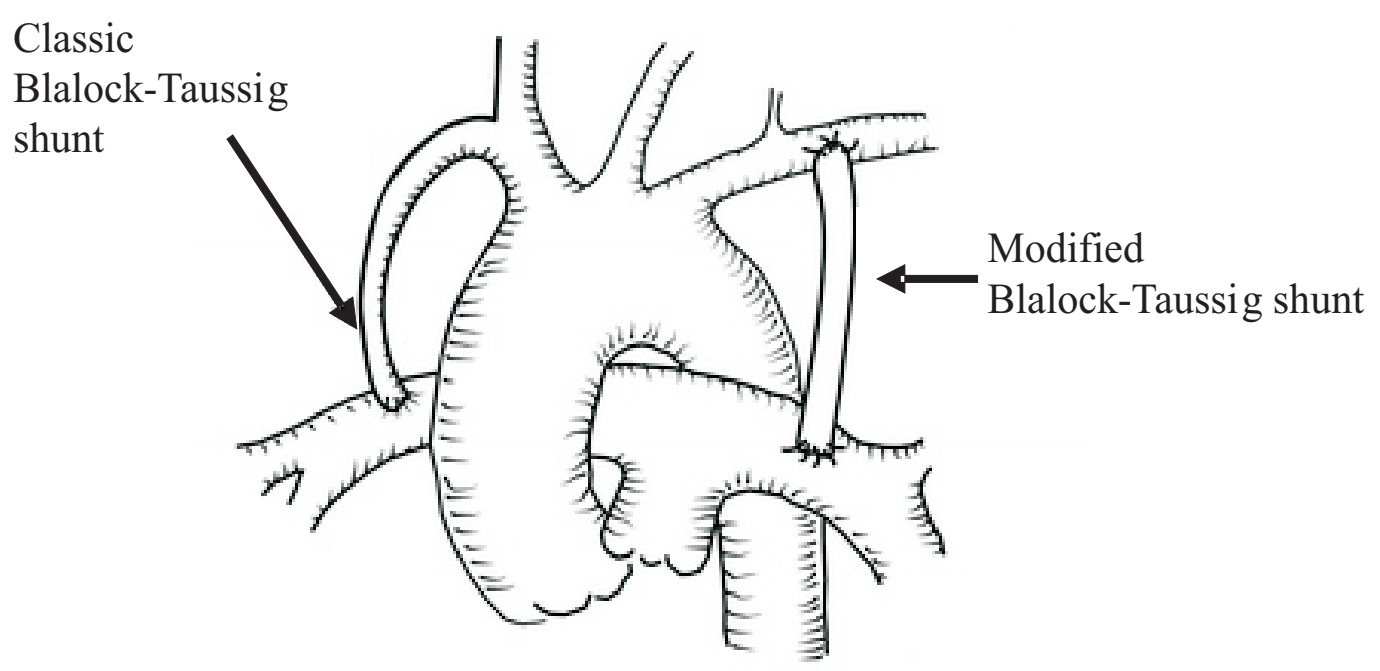

Figure 5: Modified BT shunt

\section{References}

1. Blalock A, Taussig HB. The surgical treatment of malformations of the heart in which there is pulmonary atresia.JAMA 1945;128: 189.

2. De Leval MR, McKay R, Jones M, et al. Modified BlalockTaussig shunt. J Thorac Cardiovasc Surg 1981; 81: 112.

3. Gananiga AB, Elliot MP, Sperling DR. et al. Microporous expanded polytetrafluoroethylene arterial prosthesis for construction of aorticopulmonary shunts. Experimental and clinical results. Ann Thorac Surg 1976; 21: 322-7.
4. Berger RM, Bol-Raap G, Hop WJ, et al. Heparin as a risk factor for perigraft seroma complicating the modified Blalock-Taussig shunt. J Thorac Cardiovasc Surg 1998; 116: $286-92$.

5. Coren ME, Green C, Yates R, Bush A. Complications of modified Blalock-Taussig shunts mimicking pulmonary disease. Arch Dis Child 1998; 79: 361-2. 